Comparison between volatile emissions from transgenic apples and from two representative classically bred apple cultivars

\author{
Journal Article \\ Author(s): \\ Vogler, Ute; Rott, Anja S.; Gessler, Cesare; Dorn, Silvia \\ Publication date: \\ 2010 \\ Permanent link: \\ https://doi.org/10.3929/ethz-b-000017365
}

Rights / license:

In Copyright - Non-Commercial Use Permitted

Originally published in:

Transgenic Research 19(1), https://doi.org/10.1007/s11248-009-9294-8 


\title{
Comparison between volatile emissions from transgenic apples and from two representative classically bred apple cultivars
}

\author{
Ute Vogler · Anja S. Rott · Cesare Gessler • \\ Silvia Dorn
}

Received: 9 December 2008/ Accepted: 4 June 2009/Published online: 19 June 2009

(C) Springer Science+Business Media B.V. 2009

\begin{abstract}
While most risk assessments contrast a transgenic resistant to its isogenic line, an additional comparison between the transgenic line and a classically bred cultivar with the same resistance gene would be highly desirable. Our approach was to compare headspace volatiles of transgenic scab resistant apple plants with two representative cultivars (the isogenic 'Gala' and the scab resistance gene-containing 'Florina'). As modifications in volatile profiles have been shown to alter plant relationships with non-target insects, we analysed headspace volatiles from apple plants subjected to different infection types by gas chromatography-mass spectrometry. Marked differences were found between healthy and leafminer (Phyllonorycter blancardella) infested genotypes, where emissions between the
\end{abstract}

U. Vogler · S. Dorn ( $)$

ETH Zurich, Institute of Plant Sciences/Applied

Entomology, Schmelzbergstrasse 9/LFO, 8092 Zurich,

Switzerland

e-mail: silvia.dorn@ipw.agrl.ethz.ch

C. Gessler

ETH Zurich, Institute of Integrative Biology/Plant Pathology, Universitätsstrasse 2/LFW, 8092 Zurich, Switzerland

\section{A. S. Rott}

School of Pharmacy and Biomolecular Sciences, University of Brighton, Cockcroft Building,

Moulsecoomb, Brighton BN2 4GJ, UK transgenic scab resistant line and the two cultivars differed quantitatively in four terpenes and an aromatic compound. However, these modified odour emissions were in the range of variability of the emissions recorded for the two standard cultivars that proved to be crucial references.

Keywords Malus $\times$ domestica.

Plant pathogen · Herbivory · Trophic interaction . Volatiles · Terpenes

\section{Introduction}

Non-target effects of recombinant DNA technology are of major concern in risk assessment studies (Poppy and Sutherland 2004; Romeis et al. 2008). To date, investigations of the impact of transgenic plants on non-target organisms have largely focused on insect resistant plants expressing Bacillus thuringiensis (Bt) toxins (Romeis et al. 2006), although there are also transgenic plants conveying resistance to diseases (Collinge et al. 2008). A critical issue in case-specific environmental risk assessments is the inclusion of appropriate comparisons (Andow and Zwahlen 2006; Marvier et al. 2007). A particular gap refers to direct comparisons between resistant genetically modified and resistant conventionally bred genotypes that were subjected to different infection regimes (Turlings et al. 2005; Dean and De Moraes 2006). In $B t$ crop plants, such comparisons were 
impossible as there is no conventionally bred cultivar expressing the $B t$ toxin, hence it is unclear whether or not any observed non-target effect of the transgenic plant would also be found in the respective resistant cultivar.

The current study relies on transgenic and classically bred apple genotypes targeting resistance against a key fungal pathogen in orchards worldwide, the apple scab Venturia inaequalis (Ascomycotina: Pleosporales) (MacHardy et al. 2001). This target organism is the focus of major resistance breeding programs (Gessler et al. 2006). A gene-for-gene interaction (Flor 1971) has been found for the $V f$ resistance gene region conveying resistance to this pathogen on apple trees (Malus $\times$ domestica) (Williams and Kuc 1969). Scab resistance originating from Malus floribunda 821 was introgressed into apple by conventional breeding, yielding the cultivar 'Florina'. Among a set of HcrVf genes (homologs to Cladosporium fulvum resistance genes of the $V f$ region) (Vinatzer et al. 2001) from this cultivar, HcrVf2 was cloned into the scab susceptible cultivar 'Gala' conferring resistance to scab (Belfanti et al. 2004). In the selected transgenic line, this gene is under the control of the CaMV S35 promoter and linked to the selectable marker gene nptII. One particular transformed line was lacking the target gene but still carrying the selectable marker construct; it served as control, being as susceptible as the untransformed cultivar 'Gala'. The effect of the introduced HcrVf2 gene on the target organism is equal to the effect of the $V f$ resistance introgressed by classical breeding yielding 'Florina' (Belfanti et al. 2004). However, nothing is known about the impact of scab resistant transgenic apple plants on non-target organisms associated with the apple tree.

Apart from pathogens, plants interact in their environment with other plants, herbivores, and antagonists of those herbivores. In these interactions, plants use direct and indirect systems to defend themselves (Poppy 1997; Baldwin et al. 2006). In response to herbivore attack, plants emit volatile compounds derived from different induced defence pathways (Fidantsef et al. 1999; Arimura et al. 2005; Scascighini et al. 2005). These plant volatiles include green leaf volatiles (GLV), terpenes and a wide array of aromatic compounds. The GLV comprise $\mathrm{C}_{5}$ and $\mathrm{C}_{6}$ compounds (aldehydes, alcohols and esters; Salch et al. 1995; Connor et al. 2008) synthesized via the lipoxygenase pathway as breakdown products of membrane lipids (Paré and Tumlinson 1999; Connor et al. 2008). Terpenes are synthesized via the mevalonate (MVA) or the methylerythritol 4-phosphate (MEP) pathway (Lichtenthaler et al. 1997; Aharoni et al. 2005; Dudareva et al. 2005) using the precursors isopentenyl diphosphate (Dandekar et al. 2004) and dimethylallyl diphosphate (DMAPP). Other compounds like nitriles and aromatics are synthesized via the shikimic acid pathway (Bennett and Wallsgrove 1994). Qualitative and/or quantitative changes in the volatile blends might impede tritrophic interactions with insects and therefore, potential risks have to be assessed.

Leafminers such as Phyllonorycter blancardella (Lepidoptera: Gracillariidae) are an excellent model as their epidemic outbreak leads to leaf fall and to yield decrease over consecutive seasons (Reissig et al. 1982), but such dynamics can be prevented successfully if parasitoid populations are conserved (Dorn et al. 1999). Alterations in the volatile profile of healthy or scab infested transgenic apple plants could influence useful tri-trophic interaction between plant, herbivore and natural antagonist. Here we compared the composition of headspace volatiles emitted by apple plants from four different genotypes subjected to four different infection types, as volatile blends emitted by differently induced plants could vary. The plants were (A) healthy, (B) inoculated with apple scab conidia, $(\mathbf{C})$ infested with apple leafminer larvae, or (D) pathogen inoculated and leafminer larvae infested in combination. Our approach was to compare headspace volatiles of (1) transgenic scab resistant apple plants ('Gala-trans $V f$ ') with two representative classically bred cultivars, namely (2) the isogenic line 'Gala' and (3) the scab resistant 'Florina' that contains the same HcrVf2 resistance gene as the transgenic resistant line. To evaluate a possible influence of the transgenosis per se we included (4) an additional transgenic genotype containing only the selective gene and the promoter (Table 1).

\section{Materials and methods}

Plant material

The experiments were conducted with four different apple genotypes (Table 1): a scab susceptible cultivar 
Table 1 Specifications and purpose of the four apple lines in this study

\begin{tabular}{|c|c|c|}
\hline Apple genotype & Specification & Purpose \\
\hline 'Gala' & Conventionally bred; scab susceptible & Key reference \\
\hline 'Gala-trans0' & $\begin{array}{l}\text { Transgenic; scab susceptible; with S35 promoter } \\
\text { and marker nptII }\end{array}$ & $\begin{array}{l}\text { Control } 1 \text { (for the key test line regarding transgenic } \\
\text { aspects) }\end{array}$ \\
\hline 'Gala-trans $V f$ ' & $\begin{array}{l}\text { Transgenic; scab resistant; with } H c r V f 2, \mathrm{~S} 35 \\
\text { promoter and marker } n p t I I\end{array}$ & Key test line \\
\hline 'Florina' & Conventionally bred; scab resistant with $H c r V f 2$ & $\begin{array}{l}\text { Control } 2 \text { (for the key test line regarding scab } \\
\text { resistance) }\end{array}$ \\
\hline
\end{tabular}

'Gala', a scab susceptible transgenic line 'Galatrans0' (consisting only of the selectable marker gene nptII under the control of the S35 promoter), a scab resistant transgenic line 'Gala-trans $V f$ ' (consisting of the selectable marker gene $n p t I I$ under the control of the $\mathrm{S} 35$ promoter and the $H c r V f 2$ resistance gene with S35 as promoter), and a scab resistant cultivar 'Florina'. About 2-years old grafted apple plants of the cultivars 'Gala', 'Gala-trans0', 'Gala-trans $V f$ ', and 'Florina' were planted in pots containing 1.51 substrate-perlite-sand mixture (mix ratio 6:1:1). The plants were regularly pruned and fertilized weekly (Wuxal liquid fertilizer, concentration $0.2 \%$, N:P:K 10:10:7.5, Maag Syngenta Agro, Dielsdorf, Switzerland) to keep them in a vegetative growing stage. A fully equipped closed greenhouse chamber with internal air circulation was used to grow the plants and an equal separate greenhouse chamber was used to conduct the experiments with all four apple genotypes in parallel. The controlled climatic conditions were: day temperature at $22 \pm 2^{\circ} \mathrm{C}$ and night temperature at $18 \pm 2{ }^{\circ} \mathrm{C}, 60 \pm 5 \%$ relative humidity and a photoperiod of L16:D8. Assimilation lighting was used to complete the daylight when necessary.

Pest management strategies to protect the plants against herbivores and pathogens were applied when necessary during cultivation. Against herbivory of spider mites bromopropylate (bridged diphenyl acaricide, Spomil, EC $250 \mathrm{~g} / \mathrm{l}, 15 \mathrm{ml} / 10 \mathrm{l}$ ) was sprayed and to keep them under continuous control a predatory mite population (Phytoseiulus persimilis, Andermatt Biocontrol AG, Grossdietwil, Switzerland) was established. Plants were sprayed with penconazol (triazol, Topaz Vino, EC $100 \mathrm{~g} / \mathrm{l}, 50 \mathrm{ml} / 100 \mathrm{l}$ ) against the apple powdery mildew (Podosphaera leucotricha) when necessary. The latest time of pesticide application was 14 days prior to the start of the experiment with different infection types hence the plants were not treated with pesticides during the experiments, i.e. after inoculation and herbivore infestation.

Pathogen and pathogen inoculation

Conidia of Venturia inaequalis Cooke Winter (Ascomycotina: Pleosporales) for scab inoculation were obtained from sporulating scab lesions on apple leaves collected at the Swiss Federal Research Station Agroscope Changins-Wädenswil ACW (Switzerland). Conidia were washed off from the leaves with water and their concentration was determined microscopically using a Neubauer counting chamber (Laboroptik GmbH, Friedrichsdorf, Germany). The conidia material was stored at $-20^{\circ} \mathrm{C}$ for later use.

Actively growing apple shoots with at least six fully developed leaves per plant were sprayed with conidia suspension $\left(10^{5}\right.$ conidia per $\left.\mathrm{ml}\right)$ to inoculate the whole leaf area. For the first $48 \mathrm{~h}$ the inoculated plants were kept in a plastic tent at $18^{\circ} \mathrm{C}$, darkness and a relative humidity of $100 \%$ (Gessler and Stumm 1984). Afterwards the plants were brought to a separate chamber in the greenhouse. Sporulating scab lesions on the inoculated shoots and chlorotic and necrotic lesions were visible after $24 \pm 2$ days on leaves of the two scab susceptible genotypes ('Gala' and 'Gala-trans0') but not on the scab resistant genotypes ('Gala-trans $V f$ ' and 'Florina'). This coincides with a previous paper that classified 'Florina' and 'Gala-trans Vf' (=Ga2:21) similarly regarding the level of scab resistance (Belfanti et al. 2004).

Herbivores and herbivore infestation

The colony of the herbivore Phyllonorycter blancardella (Lepidoptera: Gracillariidae) originated from 
apple orchards in South Tyrol (northern Italy). Adults were allowed to infest 2-month-old potted apple seedlings (Malus $\times$ domestica Golden Delicious open pollinated seedlings) in Plexiglas cages, covered with a glass plate and gauze on the sides. Protection of young shoots against apple powdery mildew (Podosphaera leucotricha) was achieved with penconazol (triazol, Topaz Vino, EC $100 \mathrm{~g} / 1,50 \mathrm{ml} /$ 1001 ). The conditions in the insectaries were $22 \pm 2{ }^{\circ} \mathrm{C}, 50 \pm 5 \%$ relative humidity and a photoperiod of L16:D8.

Six 2-3 days old adults were allowed to oviposit on actively growing apple shoots with at least six fully developed leaves per plant for 3 days using gauze bags $(14 \mathrm{~cm} \times 23 \mathrm{~cm})$ closed with hook-andloop fasteners. The successfully infested plants were kept in a separate greenhouse chamber. The feeding habits of sap-feeding leafminer larvae (1st to 3rd larval instar) resulted in leafmines visible on the leaf underside. After the 3rd instar hypermetamorphosis occurs, and the typically spotted tentiformed mine is formed by tissue-feeders (4th and 5th larval instar).

Combined pathogen inoculation and herbivore infestation

Actively growing apple shoots with six fully developed leaves per plant were inoculated with scab conidia suspension $\left(10^{5}\right.$ conidia per $\left.\mathrm{ml}\right)$ and kept under controlled conditions as described above for scab inoculation. Afterwards the plants were moved to a separate greenhouse chamber with controlled conditions (described above), and $55 \pm$ $1 \mathrm{~h}$ after the scab inoculation event, they were infested with six 2-3 days old adults for 3 days as described for herbivore infestation. After $24 \pm 2$ days showed the two scab susceptible genotypes ('Gala' and 'Gala-trans0') scab sporulating foliar lesions on inoculated leaves whereas no symptoms were visible on the scab resistant genotypes ('Gala-trans $V f$ ' and 'Florina') and the larvae achieved the third instar.

Infestation and/or inoculation levels used in the combined as well as in the single infection types were within the range of natural infestations, mimicking high levels of herbivore and/or pathogen attack.
Control

Healthy apple plants of the same size and age as the damaged plants were used as healthy control.

Headspace volatile collection and chemical analysis

Headspace volatiles of intact apple shoots with 12-15 leaves were collected on different sampling dates over a period of 8 months. They were analysed to identify differences in the volatile composition between the four genotypes under different infection types (healthy, leafminer infestation, scab inoculation, or combined scab inoculation and leafminer infestation) at a single, consistent time interval of $24 \pm 2$ days from the infestation and/or inoculation. Ten plants for each of the 16 genotype-treatment combinations were considered. We always tested the four genotypes within one infection type in parallel, yielding four samples per date.

Headspace volatiles were collected in a climate chamber (Conviron, Controlled Environment Ltd., Winnipeg, Canada) under controlled conditions at $22 \pm 2{ }^{\circ} \mathrm{C}, 60 \%$ relative humidity and a L16:D8 light regime for $2 \mathrm{~h}$ from apple plants, which were acclimatized for $30 \mathrm{~min}$, between $10 \mathrm{a} . \mathrm{m}$. and 3 p.m. (i.e. starting $6.5 \pm 2.5 \mathrm{~h}$ after onset of photophase). Each plant was packed in a polyester bag construct (Toppits ${ }^{\circledR}$ Brat-Schlauch, Melitta GmbH, Egerkingen, Switzerland) and wrapped at the shoot with cotton wool and Teflon tape (Alltech Socochim SA, Lausanne, Switzerland). The polyester bag was provided with an attached glass funnel and continuous circulation $(60 \mathrm{ml} / \mathrm{min})$ of charcoal filtered air (Supelcarb HC filter, Supelco, Bellefonte PA, USA) was maintained during dynamic headspace volatile collection. On the opposite side of the glass funnel, a split Teflon plate (diameter $13.5 \mathrm{~cm}$ ) was placed with a volatile trap in the middle. The volatile trap was filled with $250 \mathrm{~g}$ Supelco Tenax TA (mesh size 6080, Sigma Aldrich, Buchs, Switzerland) and sealed with Pyrex glass wool at both ends. Prior to use, the tubes were conditioned for $4 \mathrm{~h}$ at $300^{\circ} \mathrm{C}$ under a continuous stream $(50 \mathrm{ml} / \mathrm{min})$ of helium 4.6 (purity 99.96\%; Hern and Dorn 2004). The conditioned tube was airtight closed with Teflon front ferrules (Swagelok, Supelco, Bellefonte, PA, USA) until it was 
used for headspace volatile collection. The tube was tightly secured with cotton wool and Stretch-it PTFE Tape (Alltech Socochim SA, Lausanne, Switzerland) to the Teflon plate and fixed together with the polyester bag using a clasp (diameter $13.5 \mathrm{~cm}$ ). The single parts were preconditioned at $120^{\circ} \mathrm{C}$ for $2 \mathrm{~h}$ in an oven and after mounting, the whole construct was conditioned again at $120^{\circ} \mathrm{C}$ for $2 \mathrm{~h}$ in the oven before using (Stewart-Jones and Poppy 2006).

The chemical analyses and identifications are based on the method by Vallat et al. (2005), with some modifications as described below. Prior to analyses the internal standard octylbenzene ( $\sim 99.8 \%$, Fluka, Buchs, Switzerland) diluted in hexane $[100 \mathrm{ng} / \mu \mathrm{l}]$ was added to each sample by injecting directly onto the polymer. Collected volatiles were analysed using thermal desorption (Unity and Ultra, Markes Int. Ltd., Llantrisant, UK) coupled with gas chromatographymass spectrometry (HP 6890 Series GC-System and HP 5973, Hewlett Packard Company, Atlanta, GA, USA). Thermal desorption of absorbed volatiles from Tenax TA was conducted under the use of helium 5.0 (purity 99.99\%) with a prepurge time of $3 \mathrm{~min}$ (split on), followed by increasing temperature up to $300^{\circ} \mathrm{C}$ within $5 \mathrm{~min}$ (split off). Afterwards the volatiles were transferred to a cold trap $\left(-10^{\circ} \mathrm{C}\right.$ during tube desorption process), which subsequently heated up to $300^{\circ} \mathrm{C}$ at a rate of $60^{\circ} \mathrm{C} / \mathrm{min}$. The thermal desorption process was linked to the gas chromatograph-mass spectrometry system (GC-MS) via a fused silica transfer line $\left(150^{\circ} \mathrm{C}\right)$. An HP-retention-gap with deactivated fused silica, $5 \mathrm{~m}$ length and $0.25 \mathrm{~mm}$ inside diameter (Hewlett Packard Company, Atlanta, GA, USA) and a nonpolar Econo-Cap $\mathrm{EC}^{\mathrm{TM}}-5$ column with $30 \mathrm{~m}$ length, $0.25 \mathrm{~mm}$ inside diameter and $0.25 \mu \mathrm{m}$ film (Alltech Socochim SA, Lausanne, Switzerland) were used in the GC. The oven program was held at $50^{\circ} \mathrm{C}$ for $5 \mathrm{~min}$, then increased to $280^{\circ} \mathrm{C}$ at a rate of $5^{\circ} \mathrm{C} /$ min, and held at $280^{\circ} \mathrm{C}$ for 5 min with a post run at $300^{\circ} \mathrm{C}$ for $15 \mathrm{~min}$. Quadrupole and source temperature of the MS were 150 and $230^{\circ} \mathrm{C}$, using full scan method. The carrier gas was helium 5.0 (purity $99.99 \%$ ) at a constant pressure of $108 \mathrm{kPa}$. For the identification of the mass spectrometry-data ChemStation software (MSD Productivity Chem Station software, Agilent Technologies Inc., Santa Clara, CA, USA) was used linked to the NIST98 library and our own library of phytochemical compounds. In addition, the retention times of all compounds presented were compared with standard compounds purchased from chemical suppliers or obtained from other laboratories.

The chemicals used as standards in thermal desorption coupled with gas chromatography-mass spectrometry comprised (-)- $\alpha$-pinene (purity $\geq 99.0 \%$, Fluka, Buchs, Switzerland), R(+)-limonene ( $\geq 99.0 \%$, Fluka, Buchs, Switzerland), $\beta$-ocimene ( $\sim 70 \%$, Fluka, Buchs, Switzerland), ( \pm )-linalool $(\geq 95.0 \%$, Fluka, Buchs, Switzerland), $\beta$-caryophyllene $(\sim 99 \%$, Fluka, Buchs, Switzerland), $\alpha$-humulene ( $>98 \%$, Fluka, Buchs, Switzerland), (Z,E)- $\alpha$-farnesene (Givaudan-Roure, Dübendorf, Switzerland), isomeric mixture of $(E, E)-\alpha$-farnesene and $(Z, E)-\alpha$-farnesene (77\% (E,E)- $\alpha$-farnesene, $20.7 \%(Z, E)-\alpha$-farnesene, the remainder being impurities, Givaudan-Roure, Dübendorf, Switzerland), benzaldehyde ( $\geq 99.0 \%$, Fluka, Buchs, Switzerland), nonanal ( $\geq 95 \%$, Fluka, Buchs, Switzerland), decanal (94.1\%, Supelco, Bellefonte, PA, USA), acetophenone ( $\geq 99.0 \%$, Fluka, Buchs, Switzerland), geranylacetone (96\%, ABCR GmbH \& Co., Karlsruhe, Germany/Avocado Research Chemicals Ltd., Heysham, UK), (Z)-3-hexenyl acetate (99\%, ABCR, Karlsruhe, Germany), methyl salicylate ( $\geq 99 \%$, Sigma, Buchs, Switzerland), (Z)-3-hexenyl benzoate (Kosher, $\geq 97 \%$, Aldrich, Buchs, Switzerland), benzonitrile ( $\geq 99.0 \%$, Fluka, Buchs, Switzerland), and phenylacetonitrile ( $\geq 98.0 \%$, Fluka, Buchs, Switzerland).

Statistical analysis

The statistical analyses were performed using JMP 7.0.1 (SAS Institute, Cary, NC, USA) and SPSS 16.0.0 for Mac (SPSS Inc., Chicago, IL, USA). Amounts of the eighteen definitively identified compounds were calculated in [ng/l] (Trabue et al. 2006) in relation to the internal standard octylbenzene [100 $\mathrm{ng} / \mu \mathrm{l}]$ and the experimental set up including continuous airflow $[\mathrm{ml} / \mathrm{min}]$ and duration [min] of the headspace volatile collection. Mean values and standard errors were calculated for each compound analysed.

Data of all samples were included in the test for normal distribution (Shapiro-Wilk $W$ Test) and homogeneity of variance (Levene Test). To fulfil the assumption of normal distribution, data were log 10 transformed (Cuéllar 1991) and the constant 0.0001 was added to all values (Steiger et al. 2007; 
Steiner et al. 2007) to apply the log 10 transformation prior to the analyses.

To assess whether the sampling date that was always at a single distinct time interval from infestation and/or inoculation showed any effects on collected headspace volatiles, regression analyses were performed for each genotype-infection type combination separately to verify the primary interest of relationship between the variables.

Multivariate analysis of variance (MANOVA) was performed to identify significant differences between volatiles (dependent variables) emitted by the apple genotypes, subjected to the different infection types. Genotype, infection type and their interaction were the main effects in the model. MANOVA analyses within one infection type across genotypes were conducted, because the interaction could overlay effects between genotypes. If the MANOVA model was significant $(P<0.05)$, one-way analysis of variance (ANOVA) and Tukey HSD post hoc test were conducted to test for differences for individual compounds.

\section{Results}

Volatile blends and effects of infection types

Eighteen definitively identified compounds were found in the blends collected from transgenic apple lines as well as from the isogenic line 'Gala' and the resistant standard cultivar 'Florina' under different infection types. These headspace volatiles comprise eight terpenes, three aldehydes, two ketones, three esters, and two nitriles (Table 2). They coincide with compounds previously reported in association with apple (Ebel et al. 1995; Hern and Dorn 2002; Vallat et al. 2005; Casado et al. 2006). No significant effect of the sampling date (always $24 \pm 2$ days from infestation and/or inoculation) on the volatile emission was observed (all $R<0.39$; all $P>0.05$ ).

Apple genotype, infection type (healthy control, scab inoculation, leafminer infestation or a combined infection of scab and leafminer) and the genotype by infection type interaction significantly affected the volatile emission (MANOVA, Pillai's Trace, $P<0.05$ for all effects; see Table 3a). Separate analyses of emitted volatile profiles within one infection type across genotypes detected significant differences for healthy (MANOVA, Pillai's Trace $P<0.05$ ), scab inoculated (MANOVA, Pillai's Trace $P<0.05$ ) and leafminer infested (MANOVA, Pillai's Trace $P<0.05)$ plants, but a combined infection of scab and leafminer nullified any detected differences between the genotypes (see Table $3 b$ ).

Individual compounds and effect of genotype

For most of the individual compounds (Table 2), amounts released were not significantly different between the transgenic lines and the isogenic line within the same infection type. Figure 1 presents the compounds (a-e) for which significant quantitative differences were noted between genotypes. Only major compounds were considered, i.e. compounds that were positively identified in at least seven out of ten samples analysed (Table 2 indicates frequency $\mathrm{N}^{\circ}$ of detection of the compounds in a total of ten samples).

Healthy plants of the transgenic line 'Gala-trans $V f$ ' emitted significantly higher quantities of the terpene $(E, E)$ - $\alpha$-farnesene than the isogenic line 'Gala' (Fig. 1d). A similar relationship applies to 'Galatrans0'. However, these amounts were not significantly different from those found in the headspace of the classically bred scab resistant cultivar 'Florina'. There were also major quantitative differences in terpene release between the two cultivars. The tenfold amount of the sesquiterpene $(E, E)$ - $\alpha$-farnesene was emitted by 'Florina' compared to 'Gala', and similar relationships apply to the emissions of the monoterpene $\beta$-ocimene and the sesquiterpene $\beta$-caryophyllene (Fig. 1a, b, d; Table 4). Furthermore, healthy plants of 'Gala-trans $V f$ ' released significantly lower quantities of the aromatic compound phenylacetonitrile than 'Florina', while there was no significant difference between amounts released by 'Gala-trans $V f$ ' and 'Gala' (Fig. 1e; Table 4).

In contrast to scab inoculated plants, leafminer infested plants showed major quantitative differences in headspace volatiles between genotypes. While there was a significant difference in the headspace amounts of the terpenes $\beta$-ocimene, $\beta$-caryophyllene, and $(Z, E)-\alpha$-farnesene between 'Gala-trans $V f$ ' and 'Florina', no significant difference in the release of these compounds was detected when comparing the transgenic 'Gala-trans $V f$ ' to the isogenic 'Gala' (Fig. 1a-c; Table 4). 
Table 2 Volatile compounds detected in the headspace of four apple genotypes (columns)

\begin{tabular}{|c|c|c|c|c|c|c|c|c|c|c|}
\hline Compound & R.T. & & 'Gala' & $N^{\circ}$ & 'Gala-transo' & $N^{\circ}$ & 'Gala-trans $V f$ ' & $N^{\circ}$ & 'Florina' & $N^{\circ}$ \\
\hline \multicolumn{11}{|l|}{ Terpenes } \\
\hline \multirow[t]{4}{*}{$\alpha$-Pinene } & \multirow[t]{4}{*}{5.34} & $\mathbf{A}$ & $0.36 \pm 0.18$ & 10 & $0.58 \pm 0.22$ & 7 & $0.15 \pm 0.11$ & 4 & $0.25 \pm 0.17$ & 2 \\
\hline & & B & $0.04 \pm 0.02$ & 5 & $0.21 \pm 0.21$ & 1 & $0.56 \pm 0.55$ & 2 & $0.25 \pm 0.14$ & 4 \\
\hline & & $\mathbf{C}$ & $0.10 \pm 0.06$ & 4 & $0.28 \pm 0.14$ & 7 & $0.24 \pm 0.13$ & 6 & $0.48 \pm 0.26$ & 6 \\
\hline & & D & $0.10 \pm 0.04$ & 5 & $0.10 \pm 0.02$ & 9 & $0.08 \pm 0.06$ & 4 & $0.14 \pm 0.07$ & 4 \\
\hline \multirow[t]{4}{*}{ Limonene } & \multirow[t]{4}{*}{8.69} & $\mathbf{A}$ & $0.45 \pm 0.20$ & 10 & $1.32 \pm 0.33$ & 10 & $0.15 \pm 0.07$ & 7 & $0.53 \pm 0.16$ & 9 \\
\hline & & B & $0.10 \pm 0.03$ & 9 & $1.08 \pm 0.43$ & 7 & $0.40 \pm 0.24$ & 9 & $0.53 \pm 0.24$ & 9 \\
\hline & & $\mathbf{C}$ & $0.21 \pm 0.10$ & 7 & $0.33 \pm 0.15$ & 8 & $0.54 \pm 0.30$ & 10 & $0.61 \pm 0.24$ & 10 \\
\hline & & D & $0.28 \pm 0.13$ & 7 & $1.00 \pm 0.33$ & 10 & $0.85 \pm 0.41$ & 8 & $0.41 \pm 0.19$ & 9 \\
\hline \multirow[t]{4}{*}{$\beta$-Ocimene } & \multirow[t]{4}{*}{8.92} & $\mathbf{A}$ & $0.20 \pm 0.13$ & 6 & $1.39 \pm 0.77$ & 6 & $0.64 \pm 0.33$ & 8 & $12.89 \pm 5.58$ & 10 \\
\hline & & B & $0.53 \pm 0.25$ & 10 & $1.59 \pm 1.06$ & 7 & $2.20 \pm 1.76$ & 10 & $17.17 \pm 7.97$ & 10 \\
\hline & & $\mathbf{C}$ & $1.01 \pm 0.43$ & 10 & $1.37 \pm 0.82$ & 6 & $0.26 \pm 0.18$ & 8 & $20.14 \pm 8.26$ & 10 \\
\hline & & D & $1.08 \pm 0.42$ & 10 & $0.36 \pm 0.19$ & 7 & $3.70 \pm 2.47$ & 9 & $11.90 \pm 3.13$ & 10 \\
\hline \multirow[t]{4}{*}{ Linalool } & \multirow[t]{4}{*}{11.26} & $\mathbf{A}$ & $2.96 \pm 1.35$ & 10 & $2.54 \pm 1.41$ & 10 & $1.39 \pm 0.54$ & 10 & $3.94 \pm 2.03$ & 10 \\
\hline & & B & $1.16 \pm 0.61$ & 10 & $2.26 \pm 1.15$ & 9 & $2.10 \pm 1.52$ & 10 & $1.97 \pm 0.76$ & 10 \\
\hline & & $\mathbf{C}$ & $1.19 \pm 0.48$ & 10 & $1.06 \pm 0.55$ & 10 & $0.53 \pm 0.35$ & 10 & $2.27 \pm 1.18$ & 9 \\
\hline & & D & $1.78 \pm 0.59$ & 10 & $0.38 \pm 0.15$ & 8 & $0.97 \pm 0.45$ & 10 & $0.96 \pm 0.26$ & 10 \\
\hline \multirow[t]{4}{*}{$\beta$-Caryophyllene } & \multirow[t]{4}{*}{20.42} & $\mathbf{A}$ & $1.67 \pm 0.80$ & 10 & $3.21 \pm 1.77$ & 10 & $2.11 \pm 0.85$ & 10 & $17.40 \pm 7.74$ & 10 \\
\hline & & B & $2.64 \pm 1.64$ & 10 & $3.76 \pm 1.84$ & 9 & $5.22 \pm 3.79$ & 10 & $9.94 \pm 4.21$ & 10 \\
\hline & & $\mathbf{C}$ & $2.41 \pm 1.06$ & 10 & $1.26 \pm 0.71$ & 10 & $2.38 \pm 1.94$ & 10 & $9.60 \pm 4.43$ & 10 \\
\hline & & D & $4.33 \pm 2.59$ & 10 & $5.36 \pm 2.43$ & 10 & $4.23 \pm 1.86$ & 10 & $4.53 \pm 1.41$ & 10 \\
\hline \multirow[t]{4}{*}{$\alpha$-Humulene } & \multirow[t]{4}{*}{21.21} & $\mathbf{A}$ & $0.26 \pm 0.25$ & 5 & $0.19 \pm 0.12$ & 3 & $0.08 \pm 0.04$ & 6 & $0.98 \pm 0.44$ & 9 \\
\hline & & B & $0.11 \pm 0.07$ & 10 & $0.49 \pm 0.24$ & 7 & $0.96 \pm 0.82$ & 8 & $0.46 \pm 0.23$ & 8 \\
\hline & & $\mathbf{C}$ & $0.13 \pm 0.06$ & 8 & $0.05 \pm 0.03$ & 4 & $0.09 \pm 0.08$ & 2 & $0.46 \pm 0.19$ & 9 \\
\hline & & D & $0.17 \pm 0.09$ & 8 & $0.04 \pm 0.04$ & 2 & $0.14 \pm 0.07$ & 8 & $0.19 \pm 0.06$ & 8 \\
\hline \multirow[t]{4}{*}{$(Z, E)-\alpha$-Farnesene } & \multirow[t]{4}{*}{22.54} & $\mathbf{A}$ & $0.31 \pm 0.20$ & 7 & $1.77 \pm 0.93$ & 8 & $0.67 \pm 0.29$ & 10 & $2.21 \pm 0.93$ & 6 \\
\hline & & B & $0.80 \pm 0.35$ & 9 & $3.66 \pm 2.18$ & 9 & $1.63 \pm 0.96$ & 10 & $1.19 \pm 0.33$ & 10 \\
\hline & & $\mathbf{C}$ & $0.60 \pm 0.23$ & 10 & $1.30 \pm 0.75$ & 9 & $0.17 \pm 0.08$ & 8 & $1.41 \pm 0.43$ & 10 \\
\hline & & D & $1.13 \pm 0.42$ & 10 & $0.31 \pm 0.10$ & 6 & $1.18 \pm 0.52$ & 10 & $1.15 \pm 0.51$ & 9 \\
\hline \multirow[t]{4}{*}{$(E, E)-\alpha$-Farnesene } & \multirow[t]{4}{*}{23.02} & $\mathbf{A}$ & $1.60 \pm 0.88$ & 7 & $11.44 \pm 5.24$ & 10 & $9.49 \pm 4.79$ & 10 & $18.30 \pm 6.29$ & 10 \\
\hline & & B & $6.59 \pm 3.16$ & 10 & $20.73 \pm 8.32$ & 9 & $9.54 \pm 6.01$ & 10 & $14.96 \pm 5.27$ & 10 \\
\hline & & $\mathbf{C}$ & $7.50 \pm 3.41$ & 10 & $21.86 \pm 12.74$ & 10 & $2.16 \pm 0.98$ & 10 & $18.64 \pm 7.12$ & 10 \\
\hline & & D & $13.47 \pm 5.12$ & 10 & $3.84 \pm 1.08$ & 10 & $11.10 \pm 5.52$ & 10 & $12.35 \pm 4.85$ & 10 \\
\hline \multicolumn{11}{|l|}{ Aldehydes } \\
\hline \multirow[t]{4}{*}{ Benzaldehyde } & \multirow[t]{4}{*}{6.95} & $\mathbf{A}$ & $1.65 \pm 1.15$ & 10 & $1.47 \pm 0.50$ & 10 & $0.64 \pm 0.31$ & 6 & $2.24 \pm 1.15$ & 10 \\
\hline & & B & $0.21 \pm 0.09$ & 10 & $5.87 \pm 2.26$ & 10 & $0.78 \pm 0.48$ & 6 & $0.67 \pm 0.16$ & 10 \\
\hline & & $\mathbf{C}$ & $0.44 \pm 0.25$ & 8 & $1.27 \pm 0.43$ & 10 & $0.67 \pm 0.23$ & 3 & $1.73 \pm 0.99$ & 10 \\
\hline & & D & $0.48 \pm 0.16$ & 8 & $0.54 \pm 0.07$ & 10 & $4.20 \pm 3.59$ & 9 & $0.94 \pm 0.35$ & 10 \\
\hline \multirow[t]{4}{*}{ Nonanal } & \multirow[t]{4}{*}{11.19} & $\mathbf{A}$ & $2.17 \pm 0.92$ & 10 & $3.98 \pm 1.33$ & 10 & $2.04 \pm 0.85$ & 10 & $7.21 \pm 1.99$ & 10 \\
\hline & & B & $0.92 \pm 0.47$ & 10 & $4.16 \pm 1.54$ & 10 & $3.44 \pm 2.17$ & 10 & $2.79 \pm 1.00$ & 10 \\
\hline & & $\mathbf{C}$ & $1.38 \pm 0.42$ & 10 & $1.73 \pm 0.74$ & 10 & $1.68 \pm 0.85$ & 10 & $2.97 \pm 1.06$ & 10 \\
\hline & & D & $2.32 \pm 0.98$ & 10 & $0.52 \pm 0.10$ & 10 & $1.85 \pm 0.76$ & 10 & $2.33 \pm 1.04$ & 9 \\
\hline
\end{tabular}


Table 2 continued

\begin{tabular}{|c|c|c|c|c|c|c|c|c|c|c|}
\hline Compound & R.T. & & 'Gala' & $N^{\circ}$ & 'Gala-trans0' & $N^{\circ}$ & 'Gala-trans $V f$ ' & $N^{\circ}$ & 'Florina' & $N^{\circ}$ \\
\hline \multirow[t]{4}{*}{ Decanal } & \multirow[t]{4}{*}{14.44} & $\mathbf{A}$ & $1.23 \pm 0.52$ & 10 & $3.53 \pm 1.07$ & 10 & $1.77 \pm 0.71$ & 10 & $5.76 \pm 1.61$ & 10 \\
\hline & & B & $0.79 \pm 0.42$ & 10 & $5.14 \pm 1.99$ & 10 & $3.97 \pm 2.66$ & 10 & $2.35 \pm 0.86$ & 10 \\
\hline & & $\mathbf{C}$ & $1.16 \pm 0.32$ & 10 & $1.92 \pm 0.90$ & 10 & $1.44 \pm 0.71$ & 10 & $1.86 \pm 0.73$ & 10 \\
\hline & & D & $1.72 \pm 0.72$ & 10 & $0.34 \pm 0.07$ & 10 & $1.41 \pm 0.62$ & 10 & $2.04 \pm 0.85$ & 10 \\
\hline \multicolumn{11}{|l|}{ Ketone } \\
\hline \multirow[t]{4}{*}{ Acetophenone } & \multirow[t]{4}{*}{9.81} & $\mathbf{A}$ & $2.39 \pm 1.46$ & 4 & $0.63 \pm 0.34$ & 4 & $0.74 \pm 0.64$ & 2 & $3.11 \pm 1.78$ & 5 \\
\hline & & B & $0.35 \pm 0.16$ & 4 & $1.55 \pm 0.61$ & 8 & $0.60 \pm 0.42$ & 2 & $0.20 \pm 0.08$ & 5 \\
\hline & & $\mathbf{C}$ & $1.59 \pm 0.97$ & 6 & $0.38 \pm 0.15$ & 5 & $0.08 \pm 0.04$ & 4 & $2.05 \pm 1.74$ & 4 \\
\hline & & D & $0.16 \pm 0.09$ & 3 & $0.48 \pm 0.10$ & 8 & $0.55 \pm 0.33$ & 4 & $0.18 \pm 0.09$ & 4 \\
\hline \multirow[t]{4}{*}{ Geranylacetone } & \multirow[t]{4}{*}{20.75} & $\mathbf{A}$ & $0.54 \pm 0.31$ & 5 & $0.58 \pm 0.22$ & 8 & $0.88 \pm 0.36$ & 9 & $2.26 \pm 0.80$ & 9 \\
\hline & & B & $0.47 \pm 0.31$ & 8 & $1.90 \pm 0.74$ & 10 & $1.37 \pm 0.91$ & 10 & $1.04 \pm 0.44$ & 9 \\
\hline & & C & $0.60 \pm 0.23$ & 10 & $0.45 \pm 0.25$ & 9 & $0.39 \pm 0.27$ & 9 & $0.91 \pm 0.30$ & 9 \\
\hline & & D & $0.89 \pm 0.44$ & 7 & $0.05 \pm 0.03$ & 4 & $0.69 \pm 0.30$ & 9 & $0.28 \pm 0.12$ & 7 \\
\hline \multicolumn{11}{|l|}{ Esters } \\
\hline \multirow[t]{4}{*}{ (Z)-3-Hexenyl acetate } & \multirow[t]{4}{*}{7.94} & $\mathbf{A}$ & $90.52 \pm 50.34$ & 10 & $32.20 \pm 7.10$ & 10 & $56.74 \pm 18.98$ & 10 & $40.92 \pm 10.58$ & 9 \\
\hline & & B & $19.28 \pm 4.45$ & 10 & $53.56 \pm 14.58$ & 10 & $27.37 \pm 6.36$ & 10 & $39.39 \pm 13.03$ & 10 \\
\hline & & $\mathbf{C}$ & $61.52 \pm 18.15$ & 10 & $42.70 \pm 14.52$ & 10 & $21.14 \pm 10.50$ & 10 & $30.01 \pm 13.82$ & 10 \\
\hline & & D & $33.61 \pm 7.50$ & 10 & $14.73 \pm 2.43$ & 10 & $54.81 \pm 19.95$ & 10 & $32.40 \pm 13.42$ & 10 \\
\hline \multirow[t]{4}{*}{ Methyl salicylate } & \multirow[t]{4}{*}{14.01} & $\mathbf{A}$ & $0.29 \pm 0.15$ & 5 & $3.50 \pm 2.87$ & 4 & $0.96 \pm 0.58$ & 5 & $1.76 \pm 0.70$ & 8 \\
\hline & & B & $1.00 \pm 0.51$ & 7 & $7.71 \pm 4.09$ & 7 & $1.59 \pm 1.01$ & 7 & $4.61 \pm 3.15$ & 8 \\
\hline & & $\mathbf{C}$ & $1.06 \pm 0.80$ & 5 & $9.33 \pm 6.22$ & 6 & $0.63 \pm 0.35$ & 5 & $2.72 \pm 1.19$ & 7 \\
\hline & & D & $1.50 \pm 0.82$ & 8 & $0.15 \pm 0.10$ & 3 & $1.06 \pm 0.64$ & 5 & $3.30 \pm 2.16$ & 8 \\
\hline \multirow[t]{4}{*}{ (Z)-3-Hexenyl benzoate } & \multirow[t]{4}{*}{23.93} & $\mathbf{A}$ & $0.42 \pm 0.39$ & 2 & $0.87 \pm 0.73$ & 2 & $0.73 \pm 0.41$ & 5 & $2.29 \pm 0.99$ & 5 \\
\hline & & B & $0.74 \pm 0.39$ & 6 & $2.18 \pm 1.24$ & 6 & $1.63 \pm 1.26$ & 7 & $1.25 \pm 0.56$ & 9 \\
\hline & & $\mathbf{C}$ & $1.10 \pm 0.48$ & 5 & $1.63 \pm 1.04$ & 4 & $0.31 \pm 0.26$ & 3 & $1.56 \pm 0.71$ & 6 \\
\hline & & D & $0.78 \pm 0.40$ & 7 & $0.11 \pm 0.08$ & 3 & $0.49 \pm 0.28$ & 7 & $0.73 \pm 0.27$ & 8 \\
\hline \multicolumn{11}{|l|}{ Nitriles } \\
\hline \multirow[t]{4}{*}{ Benzonitrile } & \multirow[t]{4}{*}{7.12} & $\mathbf{A}$ & $0.13 \pm 0.04$ & 7 & $0.10 \pm 0.07$ & 3 & $0.01 \pm 0.01$ & 1 & $0.43 \pm 0.21$ & 5 \\
\hline & & B & $0.07 \pm 0.03$ & 8 & $0.47 \pm 0.38$ & 4 & $0.19 \pm 0.13$ & 5 & $0.07 \pm 0.06$ & 3 \\
\hline & & $\mathbf{C}$ & $0.22 \pm 0.12$ & 6 & $0.06 \pm 0.03$ & 4 & $0.02 \pm 0.01$ & 3 & $0.34 \pm 0.15$ & 7 \\
\hline & & D & $0.02 \pm 0.01$ & 3 & $0.07 \pm 0.04$ & 4 & $0.09 \pm 0.09$ & 3 & $0.06 \pm 0.04$ & 5 \\
\hline \multirow[t]{4}{*}{ Phenylacetonitrile } & \multirow[t]{4}{*}{12.41} & $\mathbf{A}$ & $0.21 \pm 0.12$ & 10 & $0.42 \pm 0.18$ & 8 & $0.05 \pm 0.04$ & 7 & $0.34 \pm 0.11$ & 10 \\
\hline & & B & $0.06 \pm 0.02$ & 10 & $0.41 \pm 0.18$ & 10 & $1.67 \pm 1.57$ & 10 & $0.13 \pm 0.06$ & 6 \\
\hline & & $\mathbf{C}$ & $0.16 \pm 0.07$ & 9 & $0.60 \pm 0.52$ & 10 & $0.13 \pm 0.09$ & 9 & $0.14 \pm 0.07$ & 8 \\
\hline & & D & $0.04 \pm 0.01$ & 6 & $0.04 \pm 0.02$ & 3 & $0.08 \pm 0.04$ & 6 & $0.13 \pm 0.07$ & 8 \\
\hline
\end{tabular}

Comparisons within a row indicate effects of genotypes within a distinct infection type: A healthy plants; $\mathbf{B}$ scab inoculated plants; $\mathbf{C}$ leafminer infested plants; D plants subject to combined scab inoculation and leafminer infestation

Mean $\pm \mathrm{SE}[\mathrm{ng} / \mathrm{l}]$ calculated for each compound analysed; R.T. retention time [Min]; $N^{\circ}$ frequency of detection of the compounds in a total of ten samples

\section{Discussion}

The transgenic scab resistant apple genotype 'Galatrans $V f$ ' emitted a quantitatively, but not qualitatively different volatile blend under certain infection types compared to either the isogenic line 'Gala', or the scab resistant classically bred cultivar 'Florina'. Such differences were found only in two of four infection types, and in five of eighteen compounds examined. Our approach was to compare traits of transgenic 
Table 3 (a) Interaction effects of apple genotype (G), infection type (I), and genotype by infection type interaction $\left(\mathbf{G}^{*} \mathbf{I}\right)$ on the emitted volatile profile of apple plants; (b) effects of apple genotype within one infection type (A healthy plants; B scab inoculated plants; C leafminer infested plants; D plants subject to combined scab inoculation and leafminer infestation) on the emitted volatile profile of apple plants

(a)

\begin{tabular}{lcccc}
\hline Effect & \multicolumn{2}{l}{ Interaction effects } & & $F$-value \\
\cline { 2 - 5 } & Hypothesis $d f$ & Error $d f$ & 3.410 & \\
\hline G [Genotype] & 54 & 387 & 2.526 & $\mathbf{0 . 0 0 1}$ \\
I [Infection] & 54 & 387 & 1.507 & $\mathbf{0 . 0 0 1}$ \\
G*I [Genotype*Infection] & 162 & 1,215 & $\mathbf{0 . 0 0 1}$ \\
\hline
\end{tabular}

(b)

\begin{tabular}{lllll}
\hline Infection type & \multicolumn{4}{l}{ Effects of apple genotype within one infection type } \\
\cline { 2 - 5 } & $d f$ & Error $d f$ & $F$-value & $P$-value \\
\hline A [healthy] & 54 & 63 & 3.046 & $\mathbf{0 . 0 0 1}$ \\
B [scab] & 54 & 63 & 1.623 & $\mathbf{0 . 0 3 2}$ \\
C [leafminer] & 54 & 63 & 1.748 & $\mathbf{0 . 0 1 7}$ \\
D [scab + leafminer] & 54 & 63 & 1.320 & 0.144 \\
\hline
\end{tabular}

MANOVA using the 18 emitted volatile compounds $\alpha$-pinene, limonene, $\beta$-ocimene, linalool, $\beta$-caryophyllene, $\alpha$-humulene, $(Z, E)$ - $\alpha$ farnesene, $(E, E)-\alpha$-farnesene, benzaldehyde, nonanal, decanal, acetophenone, geranylacetone, (Z)-3-hexenyl acetate, methyl salicylate, $(Z)$-3-hexenyl benzoate, benzonitrile and phenylacetonitrile. Number of replicates $=10$, number of genotypes $=4$, number of infection types $=4$

Bold $P$-values indicate a significant difference. $F$-value for Pillai's trace

apple plants with representative classically bred varieties. Most remarkably, headspace volatile amounts of the transgenic scab resistant genotype 'Gala-trans $V f$ ' laid within the frame given by 'Gala' and 'Florina', indicating no significant differences of this new line compared to two cultivars that are commonly planted in commercial orchards. Differences in volatile emissions among different cultivars have been reported previously from maize subject to a single infection type, and it was concluded that these maize genotypes likely vary in their attractiveness to natural antagonists of herbivores (Gouinguené et al. 2001). In the apple ecosystem, both antagonists and herbivores have been found to behaviourally respond to volatiles from healthy apple plants (Rott et al. 2005; Vallat and Dorn 2005). Furthermore, herbivores of the same or different species may be repelled by (or attracted to) volatiles from infested trees (Hern and Dorn 2002).

In the current study, volatile profiles differed between genotypes for healthy plants and for leafminer infested plants. Little differences were noted for scab inoculated plants, and none for the plants that were subjected to a combined infection of scab and leafminer. While several studies have addressed volatile emissions of one single plant genotype across different infection types (Rostás et al. 2006; Kishimoto et al. 2008), this study is to our knowledge the first comparing the volatile emissions of several genotypes in response to insect, fungal and combined infections. Our findings suggest that marked differences in volatile profiles found between various healthy or insect infested genotypes are diminished by prior scab infection. Future time course experiments, as they have been carried out for herbivore infested apple (Hern and Dorn 2001), might help to understand underlying mechanisms.

Quantitative differences between the transgenic scab resistant line and the commercial cultivars were assessed for four terpenes and an aromatic compound. Bioactivity in the apple ecosystem has been reported for several of them. The two sesquiterpene isomers $(E, E)$ - $\alpha$-farnesene and $(Z, E)$ - $\alpha$-farnesene have a similar behavioural effect on mated females of the codling moth Cydia pomonella, with low dosages being attractive and high dosages repellent 
Fig. 1 Collected headspace volatiles of (a) $\beta$-ocimene, (b) $\beta$ caryophyllene, $(\mathbf{c})(Z, E)-\alpha$-farnesene $(\mathbf{d})(E, E)-\alpha$-farnesene, and (e) phenylacetonitrile from intact apple shoots of 'Gala', 'Galatrans0', 'Gala-trans $V f$ ' and 'Florina' under different infection types: healthy, scab inoculation, leafminer infestation and a combination of scab inoculation plus leafminer infestation (mean $\pm \mathrm{SE}[\mathrm{ng} / \mathrm{l}]$ calculated for each compound analysed. Number of replicates $=10$ )

(Hern and Dorn 1999), emphasizing the importance of emitted amounts. $(E, E)-\alpha$-Farnesene also stimulates oviposition and larval movement of the codling moth (Wearing and Hutchins 1973; Bradley and Suckling 1995; Landolt et al. 2000). The sesquiterpene $\beta$-caryophyllene attracted codling moth females at a dosage measured in the headspace of the apple cultivar 'Golden Delicious' under field conditions (Vallat and Dorn 2005). Both $\beta$-caryophyllene and the monoterpene $\beta$-ocimene elicited electroantennogram responses in the antennae of codling moth males, suggesting a behavioural effect of these terpenes on this species (Casado et al. 2008). Several aromatics including benzaldehyde and benzonitrile have been reported to contribute to insect attraction of fruit trees (Piñero and Prokopy 2003; Piñero and Dorn 2007; Piñero et al. 2008), while phenylacetonitrile was behaviourally ineffective in such trials (Piñero and Dorn 2007). Each of these four terpenes and phenylacetonitrile are emitted by the transgenic apple line 'Gala-trans $V f$ ' in lower or higher amounts than either by the isogenic line 'Gala' or by the scab resistant cultivar 'Florina' under distinct infection types. Hence, we cannot exclude that these changes have behavioural consequences on insects associated with the apple tree. In fact, antagonists of the apple leafminer such as parasitoids rely on volatile emission of infested apple trees to locate their concealed living host at the stage suitable for parasitism (Dorn et al. 1999; Dutton et al. 2000).

Most importantly, however, the current study provides direct evidence that these modified odour emissions are in the range of variability of the emissions recorded for the two most relevant standard apple cultivars. Differences in chemical composition between 'Gala' and 'Florina' are not restricted to individual headspace volatiles and non-volatile fruit constituents (Kindt et al. 2007). Ratios of individual compounds are also deviating, what applies to the transgenic line 'Gala-trans $V f$ ' as well. Such differences may further contribute to differential sensitivity
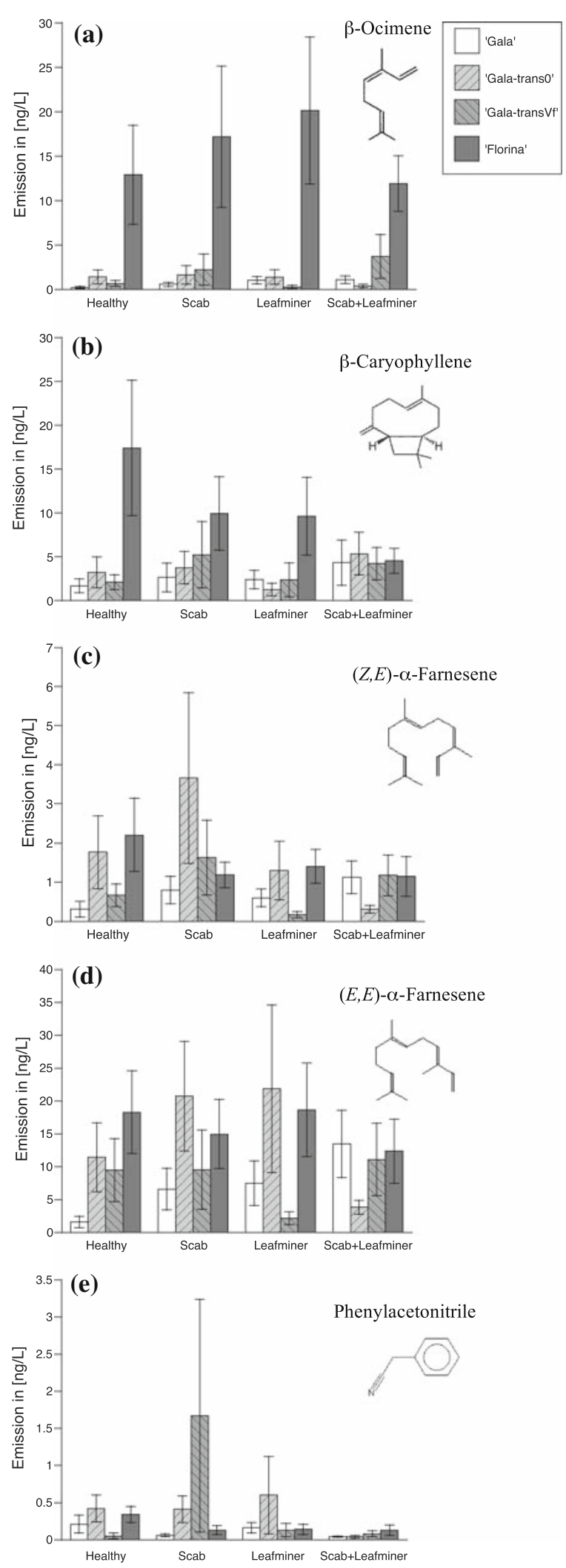
Table 4 Effects of genotype within one infection type (A healthy plants; $\mathbf{C}$ leafminer infested plants) on volatile quantities of compounds positively identified in at least seven of ten samples

\begin{tabular}{|c|c|c|c|c|c|}
\hline Compound & Infection type & $d f$ [genotype; error] & Mean square & $F$-value & $P$-value \\
\hline \multirow[t]{2}{*}{$\beta$-Ocimene } & A [healthy] & $3 ; 36$ & 12.064 & 4.428 & 0.009 \\
\hline & C [leafminer] & $3 ; 36$ & 12.713 & 6.797 & 0.001 \\
\hline \multirow[t]{2}{*}{$\beta$-Caryophyllene } & A [healthy] & $3 ; 36$ & 1.536 & 3.399 & 0.028 \\
\hline & $\mathbf{C}$ [leafminer] & $3 ; 36$ & 1.717 & 4.067 & 0.014 \\
\hline$(Z, E)-\alpha$-Farnesene & $\mathbf{C}$ [leafminer] & $3 ; 36$ & 3.320 & 3.184 & $\mathbf{0 . 0 3 5}$ \\
\hline$(E, E)-\alpha$-Farnesene & A [healthy] & $3 ; 36$ & 7.462 & 4.745 & 0.007 \\
\hline Phenylacetonitrile & A [healthy] & $3 ; 36$ & 3.927 & 3.217 & 0.034 \\
\hline
\end{tabular}

One-way ANOVA for between-subject effects. Number of replicates $=10$, number of genotypes $=4$. Bold $P$-values indicate a significant difference

of apple genotypes to insect herbivores (Qubbaj et al. 2005; Stoeckli et al. 2008) or attraction of their antagonists (Boevé et al. 1996), but we have no indication for an increased risk conferred by the genotype 'Gala-trans $V f$ ' compared to representative classically bred genotypes. Many studies on risk assessment of transgenic plants are limited to pairwise comparisons between the transgenic and the isogenic lines (Schuler et al. 2003; Turlings et al. 2005; Álvarez-Alfageme et al. 2008; Chen et al. 2008). The current investigation is, to our knowledge, the first to compare the studied trait of transgenic plants with a representative non-transgenic control cultivar that contains the same resistance gene as the transgenic plant. Our findings clearly document the significance of this approach.

Acknowledgments This project was supported by a grant of the Swiss Federal Office of the Environment (BAFU) to S. Dorn, A.S. Rott and C. Gessler. We thank H.-R. Roth for statistical, C. Fornallaz and E. Connor for technical advice, and A. Najar-Rodriguez and D. Mazzi and two anonymous reviewers for useful comments on the manuscript.

\section{References}

Aharoni A, Jongsma MA, Bouwmeester HJ (2005) Volatile science? Metabolic engineering of terpenoids in plants. Trends Plant Sci 10:594-602

Álvarez-Alfageme F, Ferry N, Castañera P et al (2008) Prey mediated effects of $\mathrm{Bt}$ maize on fitness and digestive physiology of the red spider mite predator Stethorus punctillum Weise (Coleoptera: Coccinellidae). Transgenic Res 17:943-954

Andow DA, Zwahlen C (2006) Assessing environmental risks of transgenic plants. Ecol Lett 9:196-214

Arimura G-I, Kost C, Boland W (2005) Herbivore-induced, indirect plant defences. Biochim Biophys Acta 1734:91-111
Baldwin IT, Halitschke R, Paschold A et al (2006) Volatile signaling in plant-plant interactions: "talking trees" in the genomic era. Science 311:812-815

Belfanti E, Silfverberg-Dilworth E, Tartarini S et al (2004) The HcrVf2 gene from a wild apple confers scab resistance to a transgenic cultivated variety. Proc Natl Acad Sci USA 101:886-890

Bennett RN, Wallsgrove RM (1994) Secondary metabolites in plant defence mechanisms. New Phytol 127:617-633

Boevé J-L, Lengwiler U, Tollsten L et al (1996) Volatiles emitted by apple fruitlets infested by larvae of the European apple sawfly. Phytochemistry 42:373-381

Bradley SJ, Suckling DM (1995) Factors influencing codling moth larval response to $\alpha$-farnesene. Entomol Exp Appl 75:221-227

Casado D, Gemeno C, Avilla J et al (2006) Day-night and phenological variation of apple tree volatiles and electroantennogram responses in Cydia pomonella (Lepidoptera: Tortricidae). Environ Entomol 35:258-267

Casado D, Gemeno C, Avilla J et al (2008) Diurnal variation of walnut tree volatiles and electrophysiological responses in Cydia pomonella (Lepidoptera: Tortricidae). Pest Manag Sci 64:736-747

Chen M, Zhao J-Z, Shelton AM et al (2008) Impact of singlegene and dual-gene $\mathrm{Bt}$ broccoli on the herbivore Pieris rapae (Lepidoptera: Pieridae) and its pupal endoparasitoid Pteromalus puparum (Hymenoptera: Pteromalidae). Transgenic Res 17:545-555

Collinge DB, Lund OS, Thordal-Christensen H (2008) What are the prospects for genetically engineered, disease resistant plants? Eur J Plant Pathol 121:217-231

Connor EC, Rott AS, Zeder M et al (2008) ${ }^{13}$ C-labelling patterns of green leaf volatiles indicating different dynamics of precursors in Brassica leaves. Phytochemistry 69: $1304-1312$

Cuéllar J (1991) Statistical process control for nonnormally distributed variables through the use of transformations. ASMC 91 Proceedings, pp 143-148

Dandekar AM, Teo G, Defilippi BG et al (2004) Effect of down-regulation of ethylene biosynthesis on fruit flavor complex in apple fruit. Transgenic Res 13:373-384

Dean JM, De Moraes CM (2006) Effects of genetic modification on herbivore-induced volatiles from maize. J Chem Ecol 32:713-724 
Dorn S, Schumacher P, Abivardi C et al (1999) Global and regional pest insects and their antagonists in orchards: spatial dynamics. Agric Ecosyst Environ 73:111-118

Dudareva N, Andersson S, Orlova I et al (2005) The nonmevalonate pathway supports both monoterpene and sesquiterpene formation in snapdragon flowers. Proc Natl Acad Sci USA 102:933-938

Dutton A, Mattiacci L, Dorn S (2000) Learning used as a strategy for host stage location in an endophytic hostparasitoid system. Entomol Exp Appl 94:123-132

Ebel RC, Mattheis JP, Buchanan DA (1995) Drought stress of apple trees alters leaf emissions of volatile compounds. Physiol Plant 93:709-712

Fidantsef AL, Stout MJ, Thaler JS et al (1999) Signal interactions in pathogen and insect attack: expression of lipoxygenase, proteinase inhibitor II, and pathogenesisrelated protein P4 in the tomato, Lycopersicon esculentum. Physiol Mol Plant Pathol 54:97-114

Flor HH (1971) Current status of the gene-for-gene concept. Annu Rev Phytopathol 9:275-296

Gessler C, Stumm D (1984) Infection and stroma formation by Venturia inaequalis on apple leaves with different degrees of susceptibility to scab. J Phytopathol 110:119-126

Gessler C, Patocchi A, Sansavini S et al (2006) Venturia inaequalis resistance in apple. Crit Rev Plant Sci 25:473503

Gouinguené S, Degen T, Turlings TCJ (2001) Variability in herbivore-induced odour emissions among maize cultivars and their wild ancestors (teosinte). Chemoecology 11:916

Hern A, Dorn S (1999) Sexual dimorphismus in the olfactory orientation of adult Cydia pomonella in response to $\alpha$ farnesene. Entomol Exp Appl 92:63-72

Hern A, Dorn S (2001) Induced emissions of apple fruit volatiles by the codling moth: changing patterns with different time periods after infestation and different larval instars. Phytochemistry 57:409-416

Hern A, Dorn S (2002) Induction of volatile emissions from ripening apple fruits infested with Cydia pomonella and the attraction of adult females. Entomol Exp Appl 102:145-151

Hern A, Dorn S (2004) A female-specific attractant for the codling moth, Cydia pomonella, from apple fruit volatiles. Naturwissenschaften 91:77-80

Kindt M, Orsini MC, Costantini B (2007) Improved highperformance liquid chromatography-diode array detection method for the determination of phenolic compounds in leaves and peels from different apple varieties. J Chromatogr Sci 45:507-514

Kishimoto K, Matsui K, Ozawa R et al (2008) Direct fungicidal activities of C6-aldehydes are important constituents for defence responses in Arabidopsis against Botrytis cinerea. Phytochemistry 69:2127-2132

Landolt PJ, Brumley JA, Smithhisler CL et al (2000) Apple fruit infested with codling moth are more attractive to neonate codling moth larvae and possess increased amounts of $(E, E)-\alpha$-farnesene. J Chem Ecol 26:16851699

Lichtenthaler HK, Rohmer M, Schwender J (1997) Two independent biochemical pathways for isopentenyl diphosphate and isoprenoid biosynthesis in higher plants. Physiol Plant 101:643-652

MacHardy WE, Gadoury DM, Gessler C (2001) Parasitic and biological fitness of Venturia inaequalis: relationship to disease management strategies. Plant Dis 85:1036-1050

Marvier M, McCreedy C, Regetz J et al (2007) A meta-analysis of effects of $\mathrm{Bt}$ cotton and maize on nontarget invertebrates. Science 316:1475-1477

Paré PW, Tumlinson JH (1999) Plant volatiles as a defence against insect herbivores. Plant Physiol 121:325-331

Piñero JC, Dorn S (2007) Synergism between aromatic compounds and green leaf volatiles derived from the host plant underlies female attraction in the oriental fruit moth. Entomol Exp Appl 125:185-194

Piñero JC, Prokopy RJ (2003) Field evaluation of plant odor and pheromonal combinations for attracting plum curculios. J Chem Ecol 29:2735-2748

Piñero JC, Galizia CG, Dorn S (2008) Synergistic behavioral responses of female oriental fruit moths (Lepidoptera: Tortricidae) to synthetic host plant-derived mixtures are mirrored by odor-evoked calcium activity in their antennal lobes. J Insect Physiol 54:333-343

Poppy GM (1997) Tritrophic interactions: improving ecological understanding and biological control? Endeavour 21:61-65

Poppy GM, Sutherland JP (2004) Can biological control benefit from genetically-modified crops? Tritrophic interactions on insect-resistant transgenic plants. Physiol Entomol 29:257-268

Qubbaj T, Reineke A, Zebitz CPW (2005) Molecular interactions between rosy apple aphids, Dysaphis plantaginea, and resistant and susceptible cultivars of its primary host Malus domestica. Entomol Exp Appl 115:145-152

Reissig WH, Weires RW, Forshey CG (1982) Effects of Gracillariid leafminers on apple tree growth and production. Environ Entomol 11:958-963

Romeis J, Meissle M, Bigler F (2006) Transgenic crops expressing Bacillus thuringiensis toxins and biological control. Nat Biotechnol 24:63-71

Romeis J, Bartsch D, Bigler F et al (2008) Assessment of risk of insect-resistant transgenic crops to nontarget arthropods. Nat Biotechnol 26:203-208

Rostás M, Ton J, Mauch-Mani B et al (2006) Fungal infection reduces herbivore-induced plant volatiles of maize but does not affect naïve parasitoids. J Chem Ecol 32:18971909

Rott AS, Häckermann J, Brand N et al (2005) Parasitoid exploitation of the seasonal variation in host plant volatile emission for herbivore location. Entomol Exp Appl 115:199-205

Salch YP, Grove MJ, Takamura H et al (1995) Characterization of a C-5, 13-cleaving enzyme of 13(S)-hydroperoxide of linolenic acid by soybean seed. Plant Physiol 108:12111218

Scascighini N, Mattiacci L, D'Alessandro M et al (2005) New insights in analysing parasitoid attracting synomones: early volatile emission and use of stir bar sorptive extraction. Chemoecology 15:97-104

Schuler TH, Potting RPJ, Denholm I et al (2003) Tritrophic choice experiments with Bt plants, the diamondback moth 
(Plutella xylostella) and the parasitoid Cotesia plutella. Transgenic Res 12:351-361

Steiger S, Peschke K, Francke W et al (2007) The smell of parents: breeding status influences cuticular hydrocarbon pattern in the burying beetle Nicrophorus vespilloides. Proc R Soc B 274:2211-2220

Steiner S, Mumm R, Ruther J (2007) Courtship pheromones in parasitic wasps: comparison of bioactive and inactive hydrocarbon profiles by multivariate statistical methods. J Chem Ecol 33:825-838

Stewart-Jones A, Poppy GM (2006) Comparison of glass vessels and plastic bags for enclosing living plant parts for headspace analysis. J Chem Ecol 32:845-864

Stoeckli S, Mody K, Gessler C et al (2008) QTL analysis for aphid resistance and growth traits in apple. Tree Genet Genomes 4:833-847

Trabue SL, Anhalt JC, Zahn JA (2006) Bias of tedlar bags in the measurement of agricultural odorants. J Environ Qual 35:1668-1677

Turlings TCJ, Jeanbourquin PM, Held M et al (2005) Evaluating the induced-odour emission of a $\mathrm{Bt}$ maize and its attractiveness to parasitic wasps. Transgenic Res 14:807816

Vallat A, Dorn S (2005) Changes in volatile emissions from apple trees and associated response of adult female codling moths over fruit-growing season. J Agric Food Chem 53:4083-4090

Vallat A, Gu H, Dorn S (2005) How rainfall, relative humidity and temperature influence volatile emissions from apple trees in situ. Phytochemistry 66:1540-1550

Vinatzer BA, Patocchi A, Gianfranceschi L et al (2001) Apple contains receptor-like genes homologous to the Cladosporium fulvum resistance gene family to tomato with a cluster of genes cosegregating with $V f$ apple scab resistance. Mol Plant Microbe Interact 14:508-515

Wearing CH, Hutchins RFN (1973) $\alpha$-Farnesene, a naturally occuring oviposition stimulant for the codling moth, Laspeyresia pomonella. J Insect Physiol 19:1251-1256

Williams EB, Kuc J (1969) Resistance in Malus to Venturia inaequalis. Annu Rev Phytopathol 7:223-246 